\title{
ВОЛНОВАЯ ДИНАМИКА ШИРИНЫ ГОДИЧНЫХ СЛОЕВ ДУБА
}

\author{
(С) 2014 П.М. Мазуркин ${ }^{1}$, Д.В. Тишин ${ }^{2}$ \\ ${ }^{1}$ Поволжский государственный технологический университет \\ ${ }^{2}$ Казанский (Приволжский) федеральный университет
}

Поступила 04.05.2014

\begin{abstract}
Для анализа ширины годичных слоев были взяты керны из стволов семи дубов (Quercus robur L.) на пробной площади около г. Зеленодольск Республики Татарстан. По дереву № 5 с 1774 по 2004 гг. даны математические модели ежегодной динамики ширины годичных слоев. Модель содержит более 100 асимметричных вейвлет-сигналов. Для них можно провести эвристическую идентификацию причин появления каждого колебательного возмущения дуба по радиальному приросту в ходе его развития и роста. Дана матрица параметров модели, сравнены дубы по биологическому времени и показаны графики закономерностей. Приведены результаты прогноза ширины годичного слоя дерева № 5 до 2050 г.
\end{abstract}

Ключевые слова: дуб, ширина годичных слоев, радиальный прирост, динамика, вейвлеты, сравнение

\section{ВВЕДЕНИЕ}

Для изучения строения и свойств растущих деревьев без их разрушения применяют метод керна $[2,4,5]$. Керны древесины, извлекаемые из растущих деревьев при помощи возрастных и приростных буравов Пресслера, сохраняют все свойства дерева [1], что позволяет получить необходимые данные при исследованиях возрастной структуры, прироста по диаметру, структуры и плотности древесины отдельных деревьев и древостоев.

В практикуме [2] и статьях [12-16] изложены способы измерения ширины годичного слоя с точностью до 1 мкм, а также ширины поздней и ранней древесины, с использованием технологии ГИС.

Статистическим моделированием $[10,17,22]$ выявляют волновые закономерности динамики радиального роста ствола дерева, а по полученной статистической модели прогнозируют изменение радиуса ствола дерева в перспективу и ретроспективу [2].

Опыт моделирования в дендрохронологии показан в $[3,7-9,18]$. Получены закономерности ширины годичного слоя поэтапного [16] для сосны 250 лет и минимаксного градиентного анализа ряда в 650 лет [11] ставропольской ели на керне древесины.

По данным [6] минимаксным градиентным анализом получены волновые формулы для ширины годичных слоев можжевельника возраста 808 лет.

Цель статьи - показать новый метод вейвлетанализа $[10,22]$ ширины годичного слоя дуба черешчатого. При этом предполагается, что измере-

Мазуркин Петр Матвеевич, доктор технических наук, профессор, заведующий кафедрой природообустройства, kaf_po@mail.ru; Тишин Денис Владимирович, кандидат биологических наук, доцент кафедры общей экологии, dtishin@kpfu.ru ния и датировка годичных колец до моделирования выполнены [19].

\section{РАЙОН И ОБЬЕКТ ИССЛЕДОВАНИЯ}

Дендрохронологический материал отбирался в лесу Зеленодольского лесничества, кв. 115. Координаты пробной площади широта: 55051'25"N, долгота: 4829'05"Е. Почва дерново-подзолистая. Тип леса - липняк осоково-снытевый с дубом и елью. В подлеске средней густоты преобладают лещина обыкновенная, бересклет бородавчатый и подрост липы. В травостое доминируют сныть обыкновенная и осока волосистая. Максимальный возраст дубов достигает 250 лет.

Например, дерево № 5 имеет следующие показатели: высота ствола - 24 м , диаметр на уровне груди - 77 см. Начало замера первого годичного слоя на керне древесины равно $t=0$ для 1790 г. (табл. 1). Текущий биологический возраст дуба равен $t+16$ лет, то есть дуб начал расти с 1774 г. Возраст при взятии керна на высоте 1,3 м в 2004 г. составил $A=2004-1774=230$ лет.

\section{МЕТОДИКА ИЗМЕРЕНИЙ}

Отбор кернов древесины проводился в 2005 г. возрастным буром Suunto на высоте 1,3 м по одному случайному радиусу с семи дубов. В лабораторных условиях образцы были подготовлены к измерениям по общепринятой методике [20]. Ширина годичных колец измерялась с помощью полуавтоматического измерительного комплекса LINTAB с точностью до 0,01 мм.

По данным измерений строились графики абсолютного радиального прироста, которые использовались для точной датировки годичных слоев методом перекрестной датировки [21]. Качество датировки оценивалось с помощью программы TSAPWin [23]. Перекрестная датировка это сравнение сходных графиков изменения ширины годичных слоев у разных деревьев и выбор точного места на кернах, где соответствие между ширинами максимально. 
Метод перекрестной датировки позволяет проводить относительную и абсолютную датировку времени формирования радиального прироста древесины у ствола по ширине годичных слоев.

Относительная датировка позволяет определить возраст анализируемых образцов относи- тельно друг друга, для которых календарная дата не определена.

Абсолютная датировка определяет календарную дату годичных слоев на керне. Она выполняется в том случае, если известна календарная дата взятия образца древесины хотя бы у одного дерева [19].

Таблица 1. Данные измерений ширины годичных слоев дуба № 5 и привязка к шкале времени

\begin{tabular}{|c|c|c|c|c|c|c|c|c|c|c|c|c|c|c|}
\hline Год & $\begin{array}{c}\text { Время } \\
t, \text { лет }\end{array}$ & \begin{tabular}{|c|}
$b$ \\
$\times 10^{2} \mathrm{MM}$
\end{tabular} & Год & $\begin{array}{c}\text { Время } \\
t, \text { лет }\end{array}$ & $\begin{array}{c}b, \\
\times 10^{2} \mathrm{MM}\end{array}$ & Год & $\begin{array}{l}\text { Время } \\
t, \text { лет }\end{array}$ & \begin{tabular}{|c|}
$b$ \\
$\times 10^{2} \mathrm{MM}$
\end{tabular} & Год & $\begin{array}{c}\text { Время } \\
t, \text { лет }\end{array}$ & $\begin{array}{c}b, \\
\times 10^{2} \mathrm{MM}\end{array}$ & Год & \begin{tabular}{|c|} 
Время \\
$t$, лет
\end{tabular} & $\begin{array}{c}b, \\
\times 10^{2} \mathrm{MM}\end{array}$ \\
\hline 1790 & 0 & 110 & 1833 & 43 & 162 & 1876 & 86 & 80 & 1919 & 129 & 189 & 1962 & 172 & 186 \\
\hline 1791 & 1 & 108 & 1834 & 44 & 149 & 1877 & 87 & 74 & 1920 & 130 & 264 & 1963 & 173 & 144 \\
\hline 1792 & 2 & 141 & 1835 & 45 & 105 & 1878 & 88 & 83 & 1921 & 131 & 202 & 1964 & 174 & 130 \\
\hline 1793 & 3 & 164 & 1836 & 46 & 132 & 1879 & 89 & 120 & 1922 & 132 & 126 & 1965 & 175 & 133 \\
\hline 1794 & 4 & 149 & 1837 & 47 & 142 & 1880 & 90 & 137 & 1923 & 133 & 124 & 1966 & 176 & 79 \\
\hline 1795 & 5 & 142 & 1838 & 48 & 184 & 1881 & 91 & 53 & 1924 & 134 & 84 & 1967 & 177 & 126 \\
\hline 1796 & 6 & 84 & 1839 & 49 & 121 & 1882 & 92 & 101 & 1925 & 135 & 98 & 1968 & 178 & 125 \\
\hline 1797 & 7 & 79 & 1840 & 50 & 124 & 1883 & 93 & 64 & 1926 & 136 & 101 & 1969 & 179 & 103 \\
\hline 1798 & 8 & 68 & 1841 & 51 & 100 & 884 & 94 & 110 & 1927 & & 159 & 0 & 180 & 156 \\
\hline 1799 & 9 & 64 & 1842 & 52 & 102 & 885 & 95 & 84 & 1928 & 38 & 79 & 971 & 181 & 151 \\
\hline 1800 & 10 & 110 & 1843 & 53 & 143 & 800 & 96 & 66 & 1929 & 139 & 161 & $9 / 2$ & 182 & 160 \\
\hline 1801 & 11 & 64 & 1844 & 54 & 198 & 887 & 97 & 82 & 1930 & 140 & 149 & 973 & 183 & 153 \\
\hline 1802 & 12 & 90 & 1845 & 55 & 140 & 1888 & 98 & 64 & 1931 & 141 & 156 & 1974 & 184 & 157 \\
\hline 180 & 1 & 123 & 18 & 56 & 151 & 18 & 99 & 69 & 193 & & 136 & 19 & 185 & 118 \\
\hline 180 & 14 & 96 & 18 & 57 & 126 & 890 & 100 & 119 & 193 & 3 & 112 & 1976 & 186 & 164 \\
\hline 180 & 1 & 143 & 18 & 5 & 74 & & 101 & 11 & 193 & 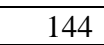 & 76 & 19 & 187 & 115 \\
\hline 1806 & & 89 & 1849 & & 93 & 1892 & 102 & 13 & 193 & & 122 & 19 & 188 & 107 \\
\hline 1807 & 17 & 101 & S & 60 & 126 & 1893 & 103 & 21 & 193 & 6 & 10 & 1979 & 189 & 70 \\
\hline 1808 & 1 & 84 & 551 & & 101 & 4 & 104 & 284 & 193 & 7 & 106 & 1980 & 190 & 88 \\
\hline 1809 & 1 & 126 & 18 & 2 & 84 & 1895 & 105 & 261 & 193 & 8 & 149 & 1 & 191 & 90 \\
\hline 181 & 20 & 94 & 18 & 6 & 99 & 189 & 106 & 222 & 19 & 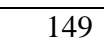 & 13 & 19 & 192 & 99 \\
\hline 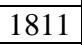 & 2 & 99 & 1 & & 70 & 507 & 107 & 18 & 19 & & 127 & 19 & 193 & 142 \\
\hline 181 & 2 & 84 & 18 & & 103 & 189 & 108 & 14 & 192 & & 150 & 40 & 194 & 134 \\
\hline 1813 & 2 & 72 & & & 79 & 18 & 109 & 11 & 192 & & 98 & 19 & 195 & 103 \\
\hline 181 & 2 & $\frac{12}{12}$ & 1 & & 74 & 1 & 110 & 213 & 19 & 3 & 112 & 19 & 196 & 84 \\
\hline 181 & 2 & 109 & 1 & & 123 & 19 & 111 & 220 & 194 & & 96 & 19 & 197 & 91 \\
\hline & & 74 & & & 98 & & 112 & 211 & 19 & & 111 & 19 & 198 & 90 \\
\hline 1817 & 2 & 79 & 18 & 7 & 80 & 190 & 113 & 128 & 194 & & 12 & 198 & 199 & 106 \\
\hline 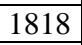 & & 78 & & & 69 & 19 & 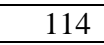 & 12 & & & 1 & & 200 & 113 \\
\hline 1819 & 2 & 76 & 18 & & 71 & 1 & 1 & 30 & 19 & & 13 & 19 & 201 & 110 \\
\hline 182 & 31 & 121 & 18 & & 73 & 19 & 1 & 297 & 194 & 9 & 14 & 19 & 202 & 92 \\
\hline & & 14 & & & & & & 23 & 41 & & & & 203 & 70 \\
\hline 1822 & 3 & 64 & 18 & 75 & 80 & 1908 & 1 & 194 & 1951 & 1 & 17 & 1994 & 204 & 56 \\
\hline 1 & 3 & 53 & & & 52 & & & 259 & & & & 19 & 205 & 74 \\
\hline 1 & 3 & 110 & 1 & & $\varepsilon$ & 19 & & 15 & 19 & & 21 & 19 & 206 & 71 \\
\hline 1825 & 3 & 205 & 18 & 7 & 132 & 19 & 1 & 21 & 1954 & & 183 & 1997 & 207 & 66 \\
\hline 1 & 3 & 20 & & & 1 & & & 1 & & & 1 & 1998 & 208 & 64 \\
\hline 1827 & 3 & 189 & 1870 & & 106 & 19 & 1 & 254 & 1956 & & 186 & 1999 & 209 & 72 \\
\hline 1 & & 164 & & & 116 & & & 12 & 195 & & 10 & 2000 & 210 & 86 \\
\hline 182 & 38 & 181 & 1872 & 8 & 54 & 1915 & 125 & 164 & 1958 & 168 & 199 & 2001 & 211 & 75 \\
\hline 1830 & 44 & 191 & 1873 & 8 & 96 & 1916 & 126 & 155 & 1959 & 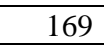 & 19 & 2002 & 212 & 66 \\
\hline 18 & 4 & 164 & & & 61 & 19 & & 18 & 19 & & 17 & 20 & 213 & 72 \\
\hline 1832 & 42 & 142 & 1875 & 85 & 59 & 1918 & 128 & 170 & 1961 & 171 & 143 & 2004 & 214 & 81 \\
\hline
\end{tabular}

\section{ЛИНЕЙНАЯ МОДЕЛЬ}

В дендрохронологии принята линейноагрегированная модель [19], отражающая формирование ширины годичного кольца:

$b=A+C+D_{1}+D_{2}+E$,

где: $A$ - тенденция роста, вызванная естественным процессом старения, $C$ - воздействие климатических факторов, $D_{1}$ - эндогенные воздействия, на- пример, плодоношение, $D_{2}$ - экзогенные воздействия, например, воздействия вредителей, загрязнения и т. д., $E$ - случайная составляющая.

Формула (1) показывает, что общий сигнал в каждый год $t$ может быть разделён на влияние ряда естественных и антропогенных факторов, воздействующих на произрастающее дерево. Однако в реальности динамика ширины годичного слоя явно 
не линейна, так как нелинейно изменчивы все факторы.

Факторы могут влиять на радиальный прирост как положительно, так и отрицательно. И это обстоятельство не позволяет выявлять адекватные закономерности, так как положительные и отрицательные влияния математически уничтожают друг друга. Из формулы (1) становится ясна основная задача экологических исследований - выделить «след», оставленный интересующим нас фактором.

Однако моделирование ширины годичных колец, как правило, проводится с помощью сплайнфункций. Недостатками являются неизвестность стыков между сплайн-функциями и допущение об одинаковых средних арифметических и равных дисперсиях у этих средних.

Фактически дисперсия всегда переменна, то есть ряд измеренных значений ширины годичных слоев скедастичен. Поэтому линейный метод дает только грубые ориентировочные оценки. При этом невозможна обратная эвристическая идентификация процессов, повлиявших на ход развития и роста дерева.

Поэтому получается, что у каждого динамического ряда в значительной степени исключены индивидуальные особенности радиального роста ствола дерева и сохранена в линейном методе только общая для данного дерева изменчивость (сигнал).

Мы предлагаем совершенно новый подход.

\section{РЯД РАДИАЛЬНОГО ПРИРОСТА СТВОЛА ДЕРЕВА КАК ЧЕРЕДА АСИММЕТРИЧНЫХ ВЕЙВЛЕТ-СИГНАЛОВ}

Физико-математический подход [2, 7, 10, 22] предполагает понимание динамического ряда ширины годичных слоев как отражения какого-то сложного и составного процесса развития и роста ствола дерева.

Сигнал - это материальный носитель информации. А информация нами понимается как мера взаимодействия. Сигнал может генерироваться, но его приём не обязателен [10, 22]. Так, например, ежегодный ряд годичных слоев людям известен умозрительно несколько сот тысяч лет, но суть его как множества сигналов до сих пор не раскрыта.

Сигналом может быть любой физический процесс, но его свойства по ряду годичных слоев пока непонятны. Получается, что изменение множества неизвестных сигналов давно известно. И ремесленники это знали давно и понимали интуитивно, например, при изготовлении музыкальных инструментов (например, скрипки Страдивари).

Поэтому примем ряд ширины годичных слоев за фрактальное множество аналоговых сигналов, изменяющихся непрерывно в шкале календарного времени. Для удобства календарную шкалу заменим шкалой времени измерений $t$.

Тогда любой асимметричный сигнал можем записать как гармоничный вейвлет $[10,20]$ вида

$$
\begin{gathered}
b=A \cos \left(\pi t / p-a_{8}\right), \\
A=a_{1} t^{a_{2}} \exp \left(-a_{3} t^{a_{4}}\right), p=a_{5}+a_{6} t^{a_{7},},
\end{gathered}
$$

где $A$ - амплитуда (половина) вейвлета (ось $y$ ), $p$ - полупериод колебания (ось $x$ ), $a_{1} \ldots a_{8}$ - параметры модели (2), значения которых по данным измерений выявляются в программной среде CurveExpert-1.40.

По формуле (2) с двумя фундаментальными постоянными $e$ и $\pi$ (иррациональные числа), образуется квантованный изнутри изучаемого явления или процесса вейвлет-сигнал. Причем квантование происходит по фрактальным уровням.

Понятие вейвлет-сигнала позволяет абстрагироваться от неизвестного явления или процесса. Мы уверены в том, что выявленные закономерности как суммы вейвлетов - будет важным событием. Как и в живой клетке: сигнал - это событие, имеющее регуляторное значение для функционирования клетки.

Есть аналогия с сигналами в ряду радиального прироста из-за живых клеток, которые вначале нужно выявить как асимметричные вейвлеты (табл. 2).

\begin{tabular}{|c|c|c|c|c|c|c|c|c|c|}
\hline \multirow{3}{*}{$\begin{array}{l}\text { Ho- } \\
\text { мep } \\
i\end{array}$} & \multicolumn{8}{|c|}{ Вейвлет $b_{i}=a_{1 i} t^{a_{2 i}} \exp \left(-a_{3 i} t^{a_{i i}}\right) \cos \left(\pi t /\left(a_{5 i}+a_{6 i} t^{a_{7 i}}\right)-a_{8 i}\right)$} & \multirow{3}{*}{$\begin{array}{c}\text { Коэфф. } \\
\text { коррел. } \\
\quad r\end{array}$} \\
\hline & \multicolumn{4}{|c|}{ амплитуда (половина) колебания } & \multicolumn{3}{|c|}{ полупериод колебания } & сдвиг & \\
\hline & $a_{1 i}$ & $a_{2 i}$ & $a_{3 i}$ & $a_{4 i}$ & $a_{5 i}$ & $a_{6 i}$ & $a_{7 i}$ & $a_{8 i}$ & \\
\hline 1 & 124,35486 & 0 & 0,0086631 & 0,74861 & 0 & 0 & 0 & 0 & \multirow{4}{*}{0,7431} \\
\hline 2 & $6,18065 \mathrm{e}-33$ & 23,68868 & 1,72906 & 0,62818 & 0 & 0 & 0 & 0 & \\
\hline 3 & 1,47924 & 1,04672 & 0,013393 & 1 & 37,44509 & 0,48830 & 0,44264 & 4,32027 & \\
\hline 4 & 79764,925 & 8,39401 & 19,40156 & 0,19160 & 20,45747 & 0 & 0 & $-0,56569$ & \\
\hline 5 & $8,13082 \mathrm{e}-35$ & 81,19211 & 0,15114 & 1,02129 & 0,97826 & 0 & 0 & 5,95901 & 0,1780 \\
\hline 6 & $-2,95406 \mathrm{e}-62$ & 36,55117 & 0,062279 & 1,28958 & 1,85804 & 0 & 0 & 3,16216 & 0,2514 \\
\hline 7 & 12,76947 & 0,29541 & 0,10908 & 0,49229 & 2,50339 & 0,0020570 & 1,22195 & $-4,67285$ & 0,3703 \\
\hline 8 & $-6,27729$ & 0,54576 & 0,30712 & 0,37334 & 11,33170 & $-0,00036758$ & 1,48945 & $-4,69337$ & 0,3127 \\
\hline 9 & 1,88998 & 10,52780 & 16,03522 & 0,23276 & 3,84305 & 0 & 0 & 0,91353 & 0,1728 \\
\hline 10 & $8,27902 \mathrm{e}-31$ & 18,29686 & 0,028758 & 1,30792 & 3,27262 & $-0,0048695$ & 0,51592 & 1,03351 & 0,2998 \\
\hline 11 & $-0,18961$ & 1,37240 & 0,023034 & 1 & 8,03973 & 0 & 0 & $-0,74639$ & 0,2281 \\
\hline 12 & $8,07674 \mathrm{e}-45$ & 28,51831 & 0,26412 & 1,00092 & 3,03788 & $-0,0010004$ & 1,13801 & $-2,85011$ & 0,3173 \\
\hline
\end{tabular}

Таблица 2. Параметры общего уравнения динамики годичного радиального прироста дуба № 5 
Наземные экосистемы

\begin{tabular}{|c|c|c|c|c|c|c|c|c|c|}
\hline \multirow{3}{*}{$\begin{array}{l}\text { Но- } \\
\text { мер } \\
i\end{array}$} & \multicolumn{8}{|c|}{ Вейвлет $b_{i}=a_{1 i} t^{a_{2 i}} \exp \left(-a_{3 i} t^{a_{i i}}\right) \cos \left(\pi t /\left(a_{5 i}+a_{6 i} t^{a_{i i}}\right)-a_{8 i}\right)$} & \multirow{3}{*}{$\begin{array}{c}\text { Коэфф. } \\
\text { коррел. } \\
r\end{array}$} \\
\hline & \multicolumn{4}{|c|}{ амплитуда (половина) колебания } & \multicolumn{3}{|c|}{ полупериод колебания } & \multirow{2}{*}{$\begin{array}{c}\text { сдВиг } \\
a_{8 i}\end{array}$} & \\
\hline & $a_{1 i}$ & $a_{2 i}$ & $a_{3 i}$ & $a_{4 i}$ & $a_{5 i}$ & $a_{6 i}$ & $a_{7 i}$ & & \\
\hline 13 & $-1,77190 \mathrm{e}-28$ & 18,56339 & 0,16713 & 1,01388 & 7,60500 & $-0,0021550$ & 1,22325 & $-3,68494$ & 0,5566 \\
\hline 14 & $5,52100 \mathrm{e}-27$ & 28,03478 & 2,54973 & 0,74307 & 4,78171 & $-0,040599$ & 0,99638 & $-4,81651$ & 0,2893 \\
\hline 15 & 31,39545 & 0 & 0,025848 & 1 & 5,90079 & $-0,090622$ & 0,95158 & 1,80007 & 0,3375 \\
\hline 16 & $-7,56653$ & 0 & 0,0060341 & 1 & 9,13846 & 0 & 0 & 3,22654 & 0,1752 \\
\hline 17 & $-7,59675$ & 0 & 0 & 0 & 15,51592 & $-0,00027403$ & 1,56536 & 0,66782 & 0,2971 \\
\hline 18 & $-8,74266$ & 0 & 0,00049328 & 1 & 1,47150 & 0 & 0 & 5,18104 & 0,3397 \\
\hline 19 & $-7,92880$ & 0 & 0,0079695 & 1 & $-91,10629$ & 96,75157 & 0,019987 & 5,06625 &, 1831 \\
\hline 20 & $2,73887 \mathrm{e}-36$ & 19,59899 & 0,10002 & 1 & 3,02573 & $-5,08663 \mathrm{e}-8$ & 1 & $-0,29248$ & 0,1572 \\
\hline 21 & $-5,84292 \mathrm{e}-28$ & 11,86111 & 0,069867 & 1 & 3,49321 & $-9,20822 \mathrm{e}-8$ & 1 & 1,40070 & 0,1667 \\
\hline 22 & $-2,24931 \mathrm{e}-21$ & 18,92424 & 0,48166 & 1 & 3,64434 & $-0,034254$ & 1 & $-2,72486$ & 0,2581 \\
\hline 23 & $1,03887 \mathrm{e}-54$ & 33,16320 & 0,25579 & 1,01188 & 1,66542 & 0 & 0 & 5,53530 & 0,1411 \\
\hline 24 & $1,14528 \mathrm{e}-63$ & 40,01659 & 0,36718 & 1 & 2,08569 & $3,39894 \mathrm{e}-8$ & 1 & $-2,43999$ & 0,2898 \\
\hline 25 & $1,23518 \mathrm{e}-25$ & 17,82508 & 0,67108 & 7576 & 1,11750 & 0 & 0 & $-5,02227$ & 0,4068 \\
\hline 26 & 8,37736 & 0 & 0,010167 & 1 & 1,31614 & 0 & 0 & $-0,9$ & 0,2181 \\
\hline 27 & $-0,51511$ & 0 & $-0,013457$ & 1 & 331 & 0 & 0 & $-1,74556$ & 0,2139 \\
\hline 28 & $-12,20143$ & 0 & 0,0087604 & 1 & 140 & 0 & 0 & $-0,82516$ & 0,3538 \\
\hline 29 & 1,13151 & 0 & $-0,0062645$ & 1 & 3058 & 0,00024158 & 1 & 4,63667 & 0,1555 \\
\hline 30 & $-0,23567$ & 0 & $-0,016215$ & 1 & 07132 & 0 & 0 & 1,16720 & 0,1796 \\
\hline 31 & $1,96790 \mathrm{e}-51$ & 31,70000 & 0,27381 & 1 & 06594 & $2,28616 \mathrm{e}-7$ & 1 & $-1,06999$ & 0,2273 \\
\hline 32 & $-5,01$ & 8,75497 & & 978 & 541 & $-0,016473$ & 04492 & $-5,31113$ & 0,3366 \\
\hline 33 & $-1,29069 \mathrm{e}-5$ & 4,43167 & 2,89311 & 0,23643 & 14,35272 & $-0,088260$ & 0,80230 & $-6,19949$ &, 2833 \\
\hline 34 & $-1,65820 \mathrm{e}-6$ & 5,92462 & 1,40986 & 0,47871 & $\begin{array}{l}1,46748 \\
\end{array}$ & 0 & 0 & 5,03203 & 0,1605 \\
\hline 35 & $1,86085 \mathrm{e}-34$ & 26,49267 & 0,45636 & 1,01481 & 19,08224 & $-0,099408$ & 1,04481 & $-5,74662$ & 0,1371 \\
\hline 36 & $-1,18217 \mathrm{e}-19$ & 11,38164 & 0,076226 & 1,00788 & 15,61352 & $-0,012663$ & 0,90261 & 1,66740 & 0,2046 \\
\hline 37 & $5,64078 \mathrm{e}-55$ & 40,81476 & 0,66015 & 1 & 146 & 0,0079956 & 1,00643 & 0,62188 &, 2853 \\
\hline 38 & $-0,00$ & 1,56469 & 754 & 1 & & $3,00752 \mathrm{e}-6$ & 1 & 3180 & 0,1369 \\
\hline 39 & 2,965 & 34277 & & 1 & & $1,14449 \mathrm{e}-8$ & 1 & & 0,4140 \\
\hline 40 & $5,58301 \mathrm{e}-98$ & 69,11868 & 61 & 1 & 365 & $-3,09359 \mathrm{e}-6$ & 1 & 5,74476 & 0,2427 \\
\hline 41 & $-1,51$ & 12,18647 & 96 & 25155 & 46 & T & 0 & & 0,3710 \\
\hline 42 & 4,35 & 3,74453 & 8709 & 87377 & 025 & 0 & $e^{2}$ & $-1,0$ & 0,2034 \\
\hline 43 & $-1,2$ & 36,76029 & 26 & & & 0 & 0 & & 0,2557 \\
\hline 44 & $2,11873 \mathrm{e}-45$ & 40,46730 & 1,09576 & 002 & 1,07211 & 0,00023247 & 21307 & 0,5 & 0,2359 \\
\hline 45 & & 0 & $-0,0$ & 1 & & $-7,46024$ & 0,11113 & 214 & 0,1032 \\
\hline 46 & & 4911 & & 2646 & & 0 & 0 & $-3,21999$ & 0,3215 \\
\hline 47 & & 0 & & 1 & 41 & 0 & 0 & & 0,2243 \\
\hline 48 & & - & 693 & 1 & &, 028188 & 0,9943 & & 0,2585 \\
\hline 49 & $-2,42842 \mathrm{e}-84$ & 65,16534 & 1,21839 & 0,99932 & 088 & $-0,0059698$ & 0,98516 & $-5,38814$ & 0,1664 \\
\hline 50 & & 10,64 & & 099955 & & $-0,0049282$ & 1,00633 & $-3,52404$ & 0,2519 \\
\hline 51 & $-2,59478 \mathrm{e}-36$ & 20,46266 & & 1,01858 & 27 & T & 0 & 1,05872 & 0,4490 \\
\hline 52 & & 22,3 & & 1,35247 & & 0 & 0 & & 0,2066 \\
\hline 53 & & 8 & & 1 & & $21687 \mathrm{e}-7$ & 1 & 773 & 0,1207 \\
\hline 54 & -6 & 4, & 963 & 582 & 36 & 0 & 0 & 2,9 & 0,3219 \\
\hline 55 & -9, & 1620 & & 027 & & 0 & 0 & & 0,1797 \\
\hline 56 & $-1,39182$ & 0 & 135 & 1 & 3,44883 & 0,024519 & 0,53424 & 1,43657 & 0,1266 \\
\hline 57 & & 250 & & 515 & & $-0,20920$ & 0,63309 & $-1,99494$ & 0,2693 \\
\hline 58 & $-2,49$ & 3 & & & & 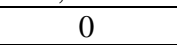 & 0 & 5,53344 & 0,2810 \\
\hline 59 & 72 & & & & & 0 & 0 & & 0,1882 \\
\hline 60 & $-7,638$ & & & 93505 & & 0080204 & 00937 & $-0,0$ & 0,1182 \\
\hline 61 & 2639 & 0,22763 & 0,0044581 & 1 & 30362 & 0 & 0 & $-1,35500$ & 0,2687 \\
\hline 62 & & & S & 0 & & 0 & 0 & $-2,55446$ & 0,2438 \\
\hline 63 & $-1,84828 \mathrm{e}-13$ & 17,52475 & 7,85362 & 0,40563 & 1,71113 & 0,16915 & 0,15185 & $-0,57125$ & 0,2613 \\
\hline 64 & & & & & & 2 & 0 & & 0,1825 \\
\hline 65 & $-4,62$ & 487 & & 1,119 & & 0 & 0 & 5,16052 & 0,2189 \\
\hline 66 & $3,86943 \mathrm{e}-35$ & 17,70810 & 72041 & 1 & 31002 & 0,0024589 & 1,40611 & 0,61598 & 0,0934 \\
\hline 67 & $-2,696$ & 50,77866 & 2 & 1,22299 & 78920 & 0 & 0 & 0,71710 & 0,1853 \\
\hline 68 & $-0,087259$ & 0 & $-0,0089403$ & 1 & 10,98965 & $-0,0016368$ & 1 & 0,24213 & 0,0523 \\
\hline 69 & & - & & 1 & & 0 & 0 & $-0,76955$ & 0,4955 \\
\hline 70 & 0,25205 & 0 & $-0,012708$ & 1 & 1,42013 & 0 & 0 & $-4,25833$ & 0,3820 \\
\hline 71 & $-1,58488$ & 0 & 0,018787 & 1 & 160,68481 & $-2,14810$ & 0,99973 & $-0,24447$ & 0,1626 \\
\hline 72 & & 0 & $-0,00$ & 1 & 24,83494 & $-0,00031560$ & 1,75372 & $-2,27120$ & 0,0589 \\
\hline 73 & $-0,059287$ & 0 & $-0,018155$ & 1 & 0,97104 & 0 & 0 & $-4,47386$ & 0,2445 \\
\hline 74 & $-0,22758$ & 0 & $-0,0068125$ & 1 & 1,13498 & 0 & 0 & 1,74628 & 0,1471 \\
\hline
\end{tabular}


Известия Самарского научного иентра Российской академии наук. 2014. T. 16, № 5

\begin{tabular}{|c|c|c|c|c|c|c|c|c|c|}
\hline \multirow{3}{*}{$\begin{array}{l}\text { Но- } \\
\text { мер } \\
i\end{array}$} & \multicolumn{8}{|c|}{ Вейвлет $b_{i}=a_{1 i} t^{a_{2 i}} \exp \left(-a_{3 i} t^{a_{i i}}\right) \cos \left(\pi t /\left(a_{5 i}+a_{6 i} t^{a_{7 i}}\right)-a_{8 i}\right)$} & \multirow{3}{*}{$\begin{array}{c}\text { Коэфф. } \\
\text { коррел. } \\
r\end{array}$} \\
\hline & \multicolumn{4}{|c|}{ амплитуда (половина) колебания } & \multicolumn{3}{|c|}{ полупериод колебания } & \multirow{2}{*}{$\begin{array}{c}\text { сдвиг } \\
a_{8 i}\end{array}$} & \\
\hline & $a_{1 i}$ & $a_{2 i}$ & $a_{3 i}$ & $a_{4 i}$ & $a_{5 i}$ & $a_{6 i}$ & $a_{7 i}$ & & \\
\hline 75 & 4,13888 & 2,65307 & 0,050260 & 0,90246 & 52,54827 & $-0,72031$ & 0,61120 & 1,25680 & 0,0622 \\
\hline 76 & 4,05864 & 0 & 0,013226 & 1 & 2,67555 & 0 & 0 & 0,14118 & 0,4596 \\
\hline 77 & $-0,98299$ & 0 & 0,0097769 & 1 & 6,53795 & $-5,76705 e-5$ & 1,28070 & 0,54411 & 0,1444 \\
\hline 78 & 0,79432 & 0,10062 & 0 & 0 & 2,31921 & $6,15415 \mathrm{e}-6$ & 1 & $-6,14807$ & 0,3764 \\
\hline 79 & 1,22028 & 0,19717 & 0 & 0 & 0,99991 & 0 & 0 & 1,60759 & 0,0164 \\
\hline 80 & $-0,93637$ & 0,34700 & 0 & 0 & 1,37257 & $6,42858 \mathrm{e}-7$ & 1 & $-0,11143$ & 0,1515 \\
\hline 81 & 0,00066962 & 1,49870 & 0 & 0 & 3,06228 & 0 & 0 & $-3,95759$ & 0,3478 \\
\hline 82 & $-7,63813 \mathrm{e}-20$ & 9,67693 & 0,0078435 & 1,27142 & 2,54503 & 0 & 0 & $-2,45830$ & 0,3249 \\
\hline 83 & $-2,10924 \mathrm{e}-29$ & 16,59752 & 0,11641 & 1 & 1,48789 & $-6,38128 \mathrm{e}-7$ & 1 & 1,09344 & 0,1474 \\
\hline 84 & $-6,43330 e-6$ & 4,13335 & 0,51283 & 0,57092 & 3,27188 & 0,0013804 & 1,05055 & 5,22402 & 0,2683 \\
\hline 85 & $-1,38294 \mathrm{e}-71$ & 46,46095 & 0,70765 & 0,92443 & 2,91431 & $-0,0016938$ & 0,78783 & $-0,27316$ & 0,3226 \\
\hline 86 & $-0,60477$ & 0,10276 & 0 & 0 & 1,90285 & 0,010277 & 0,90958 & 1,00676 & 0,3963 \\
\hline 87 & $-1,62156 \mathrm{e}-14$ & 8,20124 & 0,088515 & 0,95907 & 14,94702 & $-0,00094433$ & 1,37725 & 0,66309 & 0,0757 \\
\hline 88 & $2,48381 \mathrm{e}-12$ & 7,34602 & 0,065631 & 1 & 3,75357 & 0,15491 & 0,23022 & $-3,77147$ & 0,4776 \\
\hline 89 & $1,36688 \mathrm{e}-76$ & 45,55015 & 0,35875 & 1 & 1,75228 & $3,74092 \mathrm{e}-7$ & 1 & 6,00875 & 0,3075 \\
\hline 90 & $-3,66288 \mathrm{e}-7$ & 7,47877 & 0,34259 & 1 & 1,14660 & 0,43907 & 0,11309 & 0,50329 & 0,2979 \\
\hline 91 & $7,81674 \mathrm{e}-5$ & 2,69087 & 0,00093597 & 1,90843 & 2,31205 & 0 & 0 & $-1,46156$ & 0,1314 \\
\hline 92 & $1,93620 \mathrm{e}-30$ & 16,98333 & 0,11874 & 1 & 2,34243 & $-1,31912 \mathrm{e}-5$ & 1 & 0,97264 & 0,0974 \\
\hline 93 & $-3,25128 \mathrm{e}-12$ & 9,36199 & 0,20967 & 0,99864 & 1,48166 & $-0,00016004$ & 1,16574 & $-0,22127$ & 0,1628 \\
\hline 94 & $1,22243 \mathrm{e}-88$ & 39,98288 & 0,052087 & 0,99995 & 0,85676 & 0 & 0 & 3,47658 & 0,1848 \\
\hline 95 & $-5,04760 \mathrm{e} 5$ & 22,13341 & 49,94094 & 0,18224 & 1,64363 & 0 & 0 & $-4,82610$ & 0,2811 \\
\hline 96 & $-8,97864 \mathrm{e}-28$ & 15,80114 & 0,28510 & 0,82270 & 1,33387 & 0 & 0 & 3,56744 & 0,1924 \\
\hline 97 & $-5,76831 \mathrm{e}-54$ & 29,23315 & 0,11212 & 1,07049 & 0,94700 & 0 & 0 & 3,21891 & 0,3690 \\
\hline 98 & $9,23585 \mathrm{e}-40$ & 20,97871 & 0,10968 & 1 & 1,42082 & $4,93588 \mathrm{e}-8$ & 1 & 3,01175 & 0,1794 \\
\hline 99 & $3,60159 \mathrm{e}-58$ & 33,43511 & 0,26667 & 0,97469 & 1,17635 & 0 & 0 & 1,83692 & 0,3305 \\
\hline 100 & $5,02427 \mathrm{e}-19$ & 11,06550 & 0,090349 & 0,99616 & 4,62990 & $-0,0027739$ & 1,11923 & $-0,68996$ & 0,5026 \\
\hline 101 & $4,41306 \mathrm{e}-72$ & 38,59475 & 0,20359 & 1 & 0,59091 & $-1,35929 \mathrm{e}-9$ & 1 & 1,88000 & 0,2433 \\
\hline 102 & $3,47800 \mathrm{e}-17$ & 9,90446 & 0,35273 & 0,71249 & 1,89910 & 0 & 0 & 0,41727 & 0,2660 \\
\hline 103 & $2,77052 \mathrm{e}-50$ & 27,76253 & 0,16494 & 1,00904 & 3,78015 & $-0,00045276$ & 0,85124 & 2,00775 & 0,1911 \\
\hline 104 & $-3,55744 \mathrm{e}-65$ & 36,43236 & 0,23323 & 1 & 1,57605 & $4,42517 \mathrm{e}-8$ & 1 & 3,21817 & 0,1880 \\
\hline 105 & $-1,69099 \mathrm{e}-13$ & 20,15343 & 8,87675 & 0,44015 & 1,22966 & 0 & 0 & 4,91828 & 0,2965 \\
\hline 106 & $-0,35388$ & 0 & $-0,00041049$ & 1 & $-10,80777$ & 14,78410 & 0,017394 & 4,88175 & 0,3636 \\
\hline 107 & $-2,54618$ & 0 & 2,25359 & 1 & 0 & 0 & 0 & 0 & 0,2585 \\
\hline
\end{tabular}

\section{ТРЕНД И ДВЕ ВОЛНЫ}

Всего было получено 107 составляющих, из которых первые два члена составляют тренд (рис. 1).

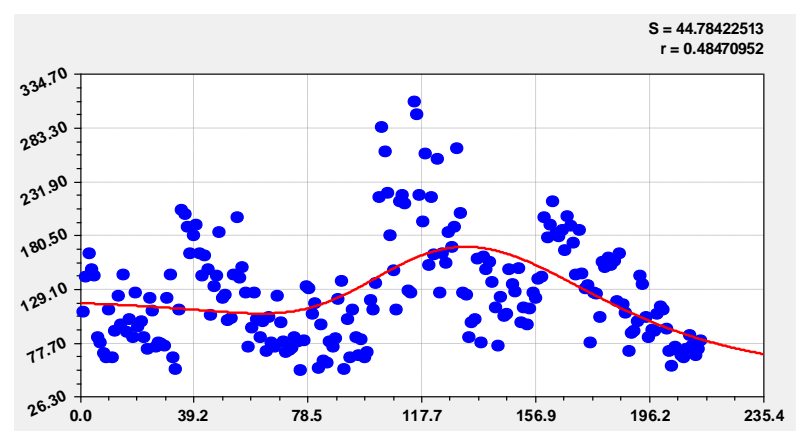

Рис. 1. Тренд динамики ширины годичного слоя дуба № 5

Затем последовательно появляются два колебания (рис. 2) с переменными амплитудой и периодом.

Эти четыре составляющие образуют формулу, с параметрами из таблицы 2 и общим коэффициентом корреляции $0,7431>0,7$ (сильная связь), вида

$$
b=b_{1}+b_{2}+b_{3}+b_{4} \text {, }
$$

$b_{1}=124,35486 \exp \left(-0,0086631 t^{0,74851}\right)$,

$b_{2}=6,18065 \cdot 10^{-33} t^{23,68868} \exp \left(-1,72906 t^{0,62818}\right)$,

$b_{3}=A_{1} \cos \left(\pi t / p_{1}-4,32027\right)$,

$A_{1}=1,47924 t^{1,04672} \exp (-0,013393 t)$,

$p_{1}=37,44509-0,48830 t^{0,44264}$,

$b_{4}=A_{2} \cos \left(\pi t / p_{2}+0,56569\right)$,

$A_{2}=79764,925 t^{8,39401} \exp \left(-19,40156 t^{0,19160}\right)$,

$p_{2}=20,45747$.

Первый член формулы (3) по закону экспоненциальной гибели всегда показывает естественную тенденцию, а второй и последующие члены статистической модели характеризуют природные или антропогенные (внешние и внутренние) влияния.

Вторая составляющая показывает стрессовое возбуждение организма дуба как генетический отклик на изменение фенотипических условий произрастания. Если бы мы знали историю развития и роста дуба за 220 лет, то вполне могли бы провести обратную эвристическую идентификацию событий.

Программная среда по своим возможностям помещает всего четыре составляющие (рис. 3). 


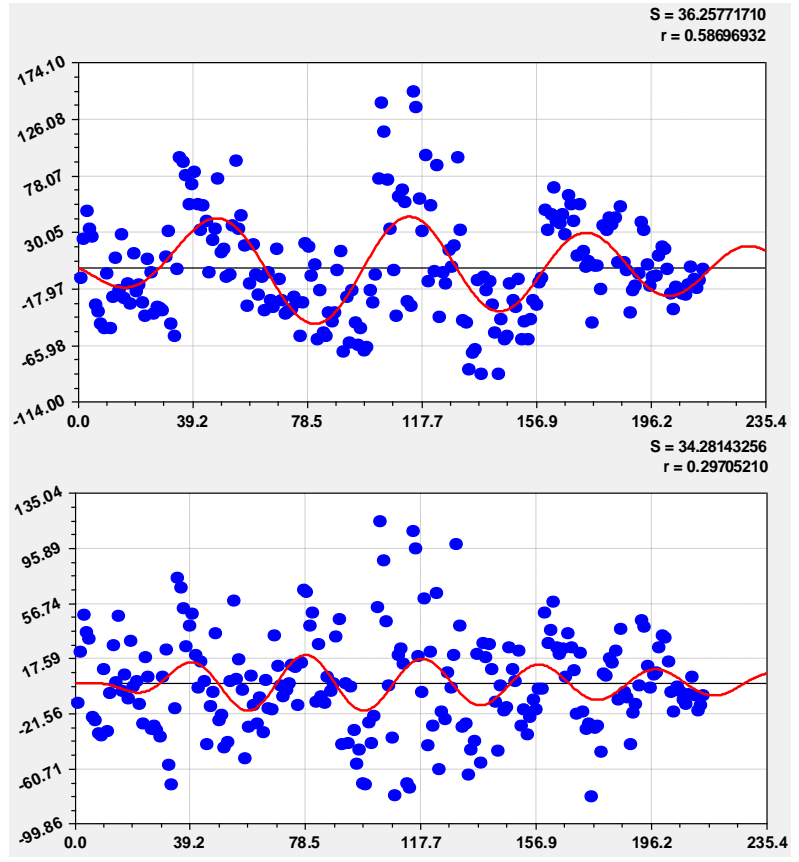

Рис. 2. Две волны колебательного возмущения

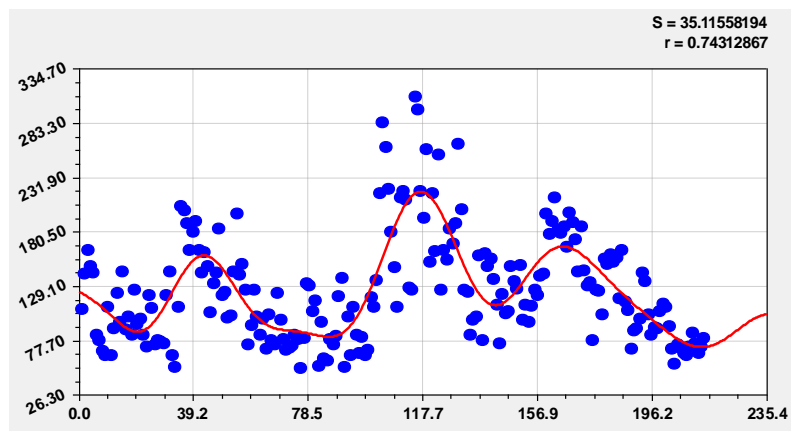

Рис. 3. График модели (3) с четырьмя членами

\section{АНАЛИЗ ПАРАМЕТРОВ МОДЕЛИ}

Интерес представляет изменение амплитуды колебания $2 a_{5 i}$ в 1790 г.

Вейвлет № 71 имеет максимальный начальный период $2 \times 160,68481 \approx 321,4$ года. А минимальный период 1,08 года наблюдается у вейвлета № 37 .

При этом все волновые члены общей формулы делятся на две группы:

a) конечномерные вейвлеты 3-14, 20-25, 31-44, $46,49-55,57-67,75,78-105$ (у них $a_{2 i} \neq 0$ );

б) бесконечномерные вейвлеты 15-19, 26-30, 45, 47, 48, 56, 68-74, 76, 77, 106 (у них $a_{2 i}=0$ ).

Особое место занимает член № 107 , показывающий необходимость учета биологического времени.

\section{ВЛИЯНИЕ БИОЛОГИЧЕСКОГО ВРЕМЕНИ}

Оно равно $t_{B}=t+16$ лет, когда жёлудь дуба №5 пророс в 1774 г. Очевидно, что в первый год у проростка ширина годичного слоя равна нулю.

При таком допущении получается, что тренд должен состоять из двух биотехнических законов $[10,20]$. Добавим в табл. 1 строку при условии $t=-16$ ширину $b=0$ и изменим шкалу $t_{B}=t+16$.
После идентификации получен (рис. 4) тренд

$b=5,20843 t_{B}{ }^{0,93949} \exp \left(-1,41944 \cdot 10^{-5} t_{B}^{2,65520}\right)+$

$+2,98403 \cdot 10^{-20} t_{B}{ }^{15,28664} \exp \left(-1,48693 t_{B}{ }^{0,57489}\right)$.

По сравнению с рисунком 1 коэффициент корреляции стал равным 0,5227 $>0,4847$. Применение биологического времени, вместо времени измерений, дает более адекватные статистические модели.

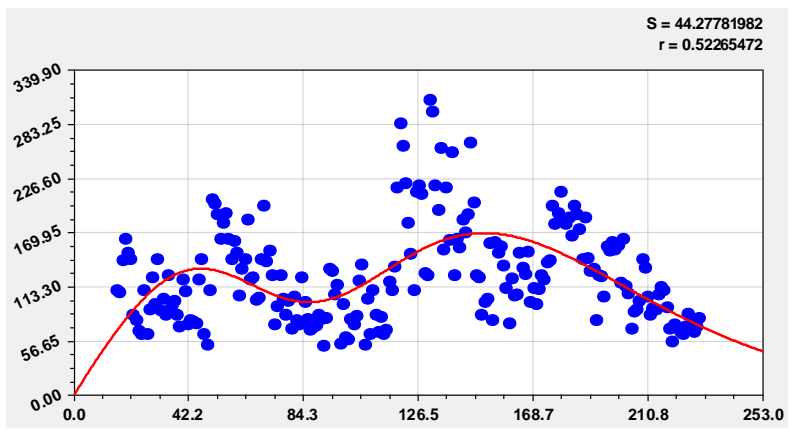

Рис. 4. График модели (4) в виде двух биотехнических законов

\section{ДРУГИЕ ДУБЫ}

Проверим общий закон $[10,20]$ на других шести дубах (табл. 3 и рис. 5).

Дубы имеют следующее время в начале замера последнего от периферии ствола годичного слоя: № $1-9$ лет; № 2 - 11; № 3 - 10; № 4 - 38; № 5 - 16; № $6-15$; № $7-34$ года.

Полный по биологическому времени керн дает лучшие результаты и по моделированию.

Например, дуб № 4 дал только одну составляющую от общей формулы тренда

$$
\begin{gathered}
b_{B}=a_{1} t_{B}{ }^{a_{2}} \exp \left(-a_{3} t_{B}{ }^{a_{4}}\right)+ \\
+a_{5} t_{B}{ }^{{ }_{6}} \exp \left(-a_{7} t_{B}{ }^{a_{8}}\right) .
\end{gathered}
$$

Наибольшую адекватность получил дуб № 3, а наименьшую по коэффициенту корреляции - № 6.

\section{ФРАКТАЛЬНЫЕ ГРУППЫ ВЕЙВЛЕТОВ}

Всего были идентифицированы 106 вейвлетов (107-е уравнение вспомогательное из-за непринятия шкалы биологического времени) по семи группам составляющих общей модели.

Группировка вейвлетов выполнена по скачкам снижения максимальных остатков по модулю $\left|\varepsilon_{\max }\right|$, как это показано в табл. 4.

Нулевой номер члена общей модели соответствует среднему арифметическому значению $\bar{b}$.

Цена деления прибора равна 0,01 мм или 10 мкм. Тогда погрешность измерения будет равна \pm 5 мкм. Группы вейвлетов выделены по шкале остатков (абсолютной погрешности моделирования): 1) более $200 \times 5=1000$ мкм; 2) от 1000 до 500 мкм; 3) 500 - 250 мкм; 4) 250 - 125 мкм; 5) 125 - 60 мкм; 6) 60 - 40 мкм; 7) менее 40 мкм (табл. 4). 

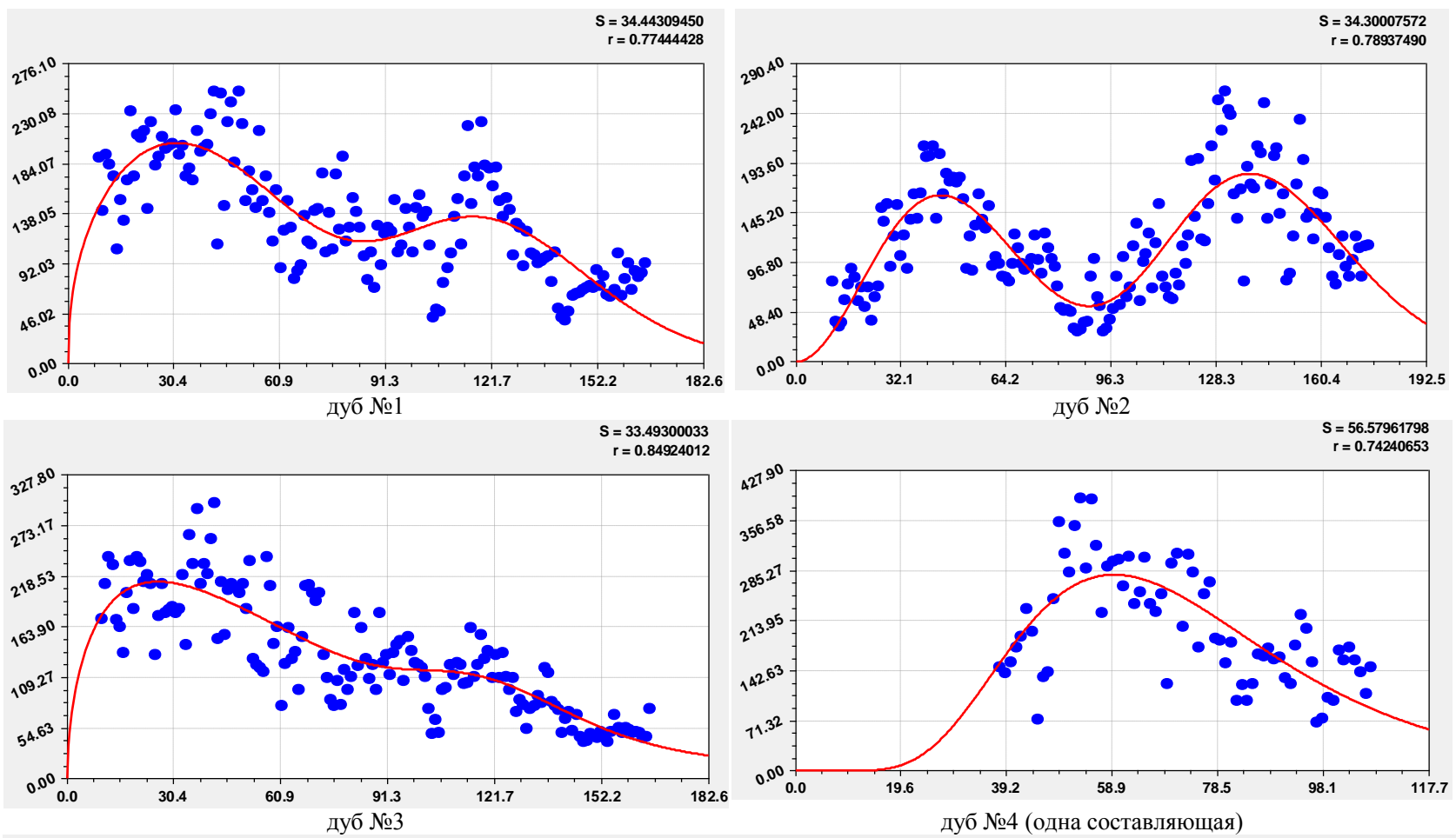

$S=43.48628970$
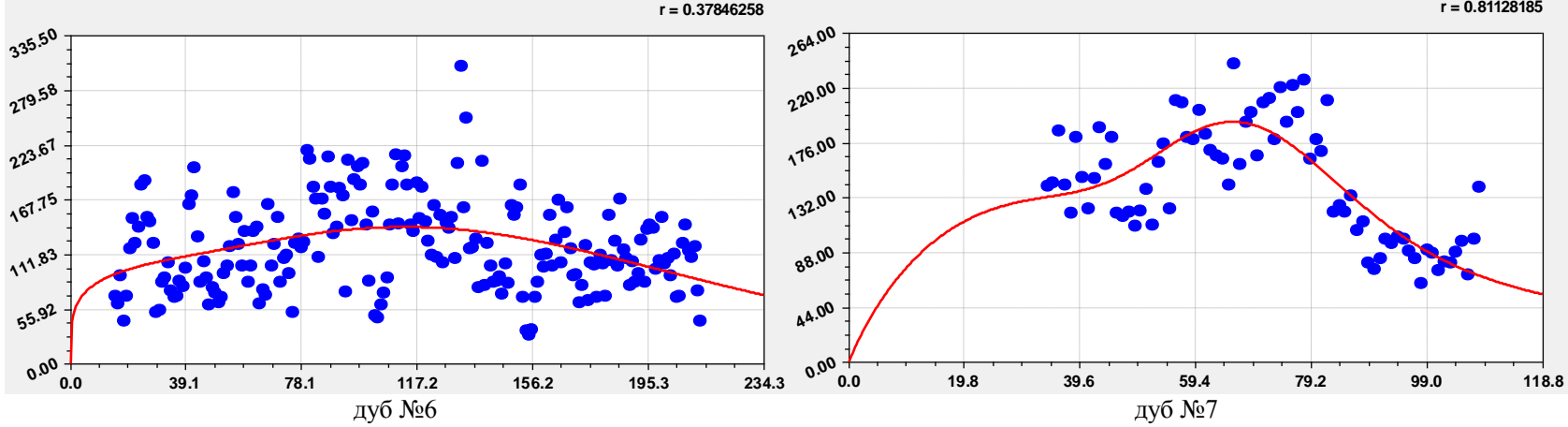

Рис. 5. Графики влияния биологического времени на тренд ширины годичного слоя у шести дубов

Таблица 3. Параметры тренда динамики ширины годичного слоя дубов от биологического времени

\begin{tabular}{|c|c|c|c|c|c|c|c|c|c|}
\hline \multirow{3}{*}{$\begin{array}{l}\text { Но- } \\
\text { мер } \\
\text { дуба }\end{array}$} & \multicolumn{8}{|c|}{ Тренд $b_{B}=a_{1} t_{B}{ }^{a_{2}} \exp \left(-a_{3} t_{B}^{a_{4}}\right)+a_{5} t_{B}^{a_{6}} \exp \left(-a_{7} t_{B}^{a_{8}}\right)$} & \multirow{3}{*}{$\begin{array}{c}\text { Коэфф. } \\
\text { коррел. } \\
r\end{array}$} \\
\hline & \multicolumn{4}{|c|}{ амплитуда (половина) колебания } & \multicolumn{3}{|c|}{ полупериод колебания } & сдвиг & \\
\hline & $a_{1}$ & $a_{2}$ & $a_{3}$ & $a_{4}$ & $a_{5}$ & $a_{6}$ & $a_{7}$ & $a_{8}$ & \\
\hline 1 & 59,58902 & 0,41593 & 0,00017844 & 2,04635 & $3,28122 \mathrm{e}-32$ & 20,30193 & 0,16373 & 0,99680 & 0,7744 \\
\hline 2 & 0,34295 & 1,87453 & 0,00048048 & 2,00097 & $4,71973 \mathrm{e}-38$ & 22,34916 & 0,059256 & 1,17072 & 0,7894 \\
\hline 3 & 63,62527 & 0,53589 & 0,020718 & 4 & $1,96918 \mathrm{e}-53$ & 32,97515 & 0,27359 & 1 & 0,8492 \\
\hline 4 & $1,74949 \mathrm{e} 8$ & 28,43590 & 52,76943 & 0,21978 & 0 & 0 & 0 & 0 & 0,7424 \\
\hline 5 & 52,08428 & 0,93949 & $1,41944 \mathrm{e}-5$ & 2,65520 & $2,98403 \mathrm{e}-20$ & 15,28664 & 1,48693 & 0,57489 & 0,5227 \\
\hline 6 & 52,58525 & 0,21338 & 0,00020407 & 1,61246 & $9,15608 \mathrm{e}-7$ & 4,49569 & 0,031274 & 1 & 0,3785 \\
\hline 7 & 11,98383 & 0,91299 & 0,024203 & 1 & $1,58158 \mathrm{e}-28$ & 21,19486 & 0,30877 & 1 & 0,8113 \\
\hline
\end{tabular}

\section{АНАЛИЗ ФРАКТАЛЬНОСТИ СУММЫ ВЕЙВЛЕТОВ}

Разные по форме сигналы самоподобны, т.е. фрактальны через общую модель типа (2).

Известно, что фракталы подобны через закон Мандельброта $y=a_{1} \exp \left(-a_{2} x\right)$. Для фрактальной модели суммы вейвлетов показателем стала максимальная абсолютная погрешность (остаток) $\left|\varepsilon_{\max }\right|$.

По данным табл. 4 получили (рис. 6) формулу

$$
\begin{aligned}
\left|\varepsilon_{\max }\right|= & 1829,860 \exp \left(-0,15483 i^{0,70934}\right)+ \\
& +A \cos (\pi i / p-0,66347),
\end{aligned}
$$

$$
\begin{aligned}
& A=58,40831 i^{0,86288} \exp (-0,11493 i), \\
& p=0,87957+0,017078 i^{1,57394} .
\end{aligned}
$$




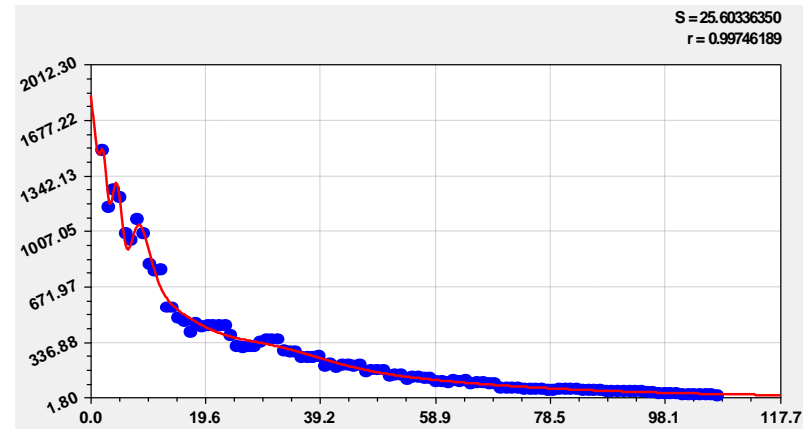

Рис. 6. График формулы (6) фрактального изменения остатков (абсолютной погрешности) от влияния номера составляющей
Таким образом, асимметричный вейвлет (2) позволяет с высокой адекватностью при коэффициенте корреляции 0,9975 показывает возможность количественного описания неизвестных в прошлом процессов поведения дуба № 5. Для эвристической идентификации прошлого поведения необходимы результаты феноменологических наблюдений.

Графики вейвлетов с наибольшими значениями коэффициента корреляции даны на рис. 7.

Амплитудно-частотный анализ каждого вейвлета позволит определить причины поведения растения. При этом на дуб влияет множество процессов.

Таблица 4. Фрактальное снижение остатков (мкм) после составляющих модели (табл. 2)

\begin{tabular}{|c|c|c|c|c|c|c|c|c|c|c|c|c|c|c|c|c|c|}
\hline \multicolumn{2}{|c|}{1 группа } & \multicolumn{2}{|c|}{2 группа } & \multicolumn{4}{|c|}{3 группа } & \multicolumn{4}{|c|}{4 группа } & \multicolumn{2}{|c|}{5 группа } & \multicolumn{2}{|c|}{6 группа } & \multicolumn{2}{|c|}{7 группа } \\
\hline$i$ & $\left|\varepsilon_{\max }\right|$ & $i$ & $\left|\varepsilon_{\max }\right|$ & $i$ & $\left|\varepsilon_{\max }\right|$ & $i$ & $\left|\varepsilon_{\max }\right|$ & $i$ & $\left|\varepsilon_{\max }\right|$ & $i$ & $\left|\varepsilon_{\max }\right|$ & $i$ & $\left|\varepsilon_{\max }\right|$ & $i$ & $\left|\varepsilon_{\max }\right|$ & $i$ & $\left|\varepsilon_{\max }\right|$ \\
\hline 0 & 1831 & 9 & 997 & 15 & 490 & 28 & 318 & 40 & 196 & 50 & 168 & 59 & 107 & 77 & 59 & 95 & 38 \\
\hline 2 & 1501 & 10 & 813 & 16 & 470 & 29 & 341 & 41 & 209 & 51 & 135 & 60 & 107 & 78 & 53 & 96 & 35 \\
\hline 3 & 1155 & 11 & 769 & 17 & 405 & 30 & 353 & 42 & 188 & 52 & 143 & 61 & 99 & 79 & 53 & 97 & 32 \\
\hline 4 & 1259 & 12 & 776 & 18 & 455 & 31 & 353 & 43 & 203 & 53 & 143 & 62 & 108 & 80 & 58 & 98 & 32 \\
\hline 5 & 1213 & 13 & 550 & 19 & 438 & 32 & 353 & 44 & 203 & 54 & 120 & 63 & 107 & 81 & 60 & 99 & 31 \\
\hline 6 & 997 & 14 & 550 & 20 & 441 & 33 & 291 & 45 & 198 & 55 & 132 & 64 & 108 & 82 & 57 & 100 & 30 \\
\hline 7 & 958 & & & 21 & 440 & 34 & 282 & 46 & 202 & 56 & 128 & 65 & 94 & 83 & 58 & 101 & 26 \\
\hline \multirow[t]{11}{*}{8} & 1082 & & & 22 & 440 & 35 & 282 & 47 & 165 & 57 & 125 & 66 & 98 & 84 & 53 & 102 & 26 \\
\hline & & & & 23 & 439 & 36 & 253 & 48 & 171 & 58 & 125 & 67 & 98 & 85 & 54 & 103 & 26 \\
\hline & & & & 24 & 379 & 37 & 253 & 49 & 171 & & & 68 & 94 & 86 & 53 & 104 & 26 \\
\hline & & & & 25 & 314 & 38 & 249 & & & & & 69 & 92 & 87 & 53 & 105 & 26 \\
\hline & & & & 26 & 311 & 39 & 254 & & & & & 70 & 64 & 88 & 47 & 106 & 25 \\
\hline & & & & 27 & 315 & & & & & & & 71 & 64 & 89 & 46 & 107 & 18 \\
\hline & & & & & & & & & & & & 72 & 66 & 90 & 46 & & \\
\hline & & & & & & & & & & & & 73 & 67 & 91 & 46 & & \\
\hline & & & & & & & & & & & & 74 & 59 & 92 & 43 & & \\
\hline & & & & & & & & & & & & 75 & 61 & 93 & 43 & & \\
\hline & & & & & & & & & & & & 76 & 61 & 94 & 43 & & \\
\hline
\end{tabular}

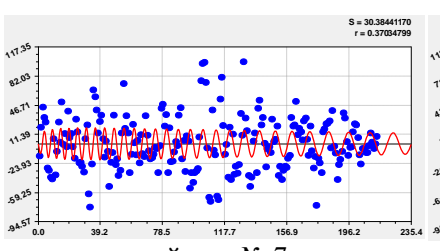

вейвлет № 7
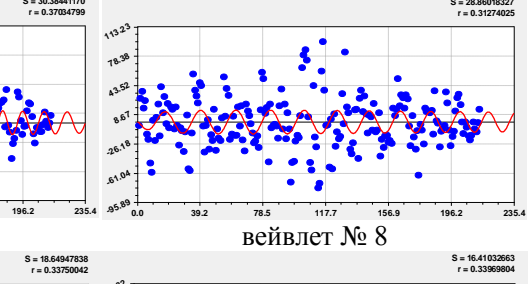

вейвлет № 8

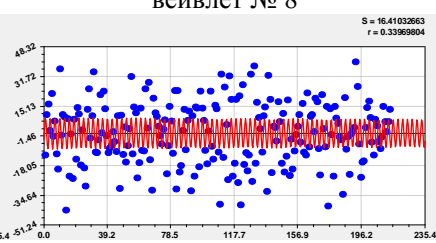

вейвлет № 18

вейвлет № 15

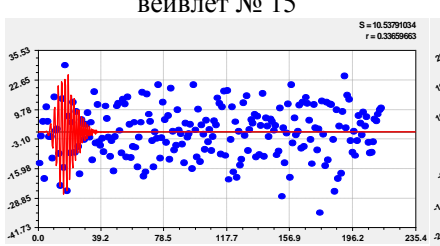

вейвлет № 32

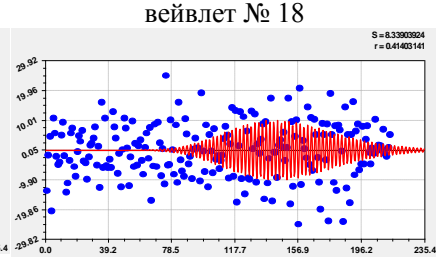

вейвлет № 39

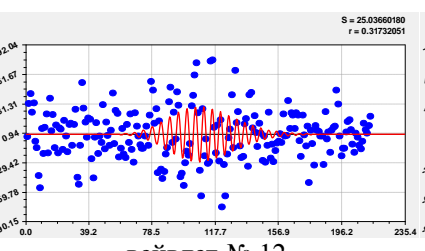

вейвлет № 12

$s=13.9072$

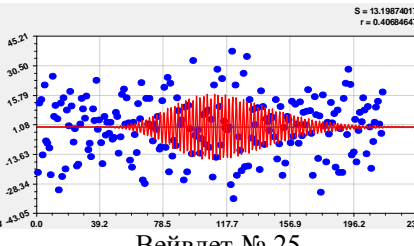

Вейвлет № 25

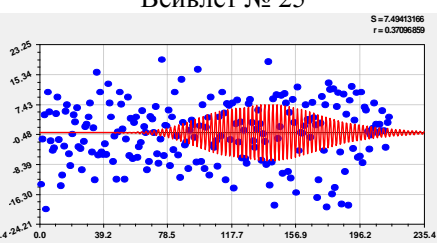

вейвлет № 41

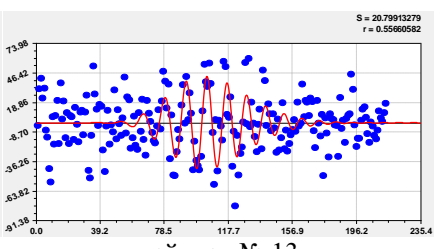

вейвлет № 13

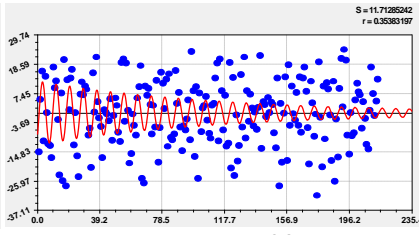

вейвлет № 28

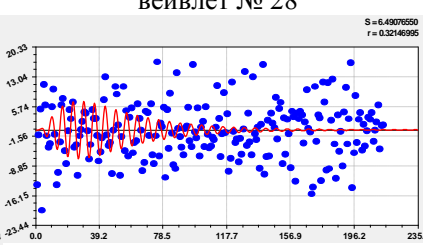

вейвлет № 46 

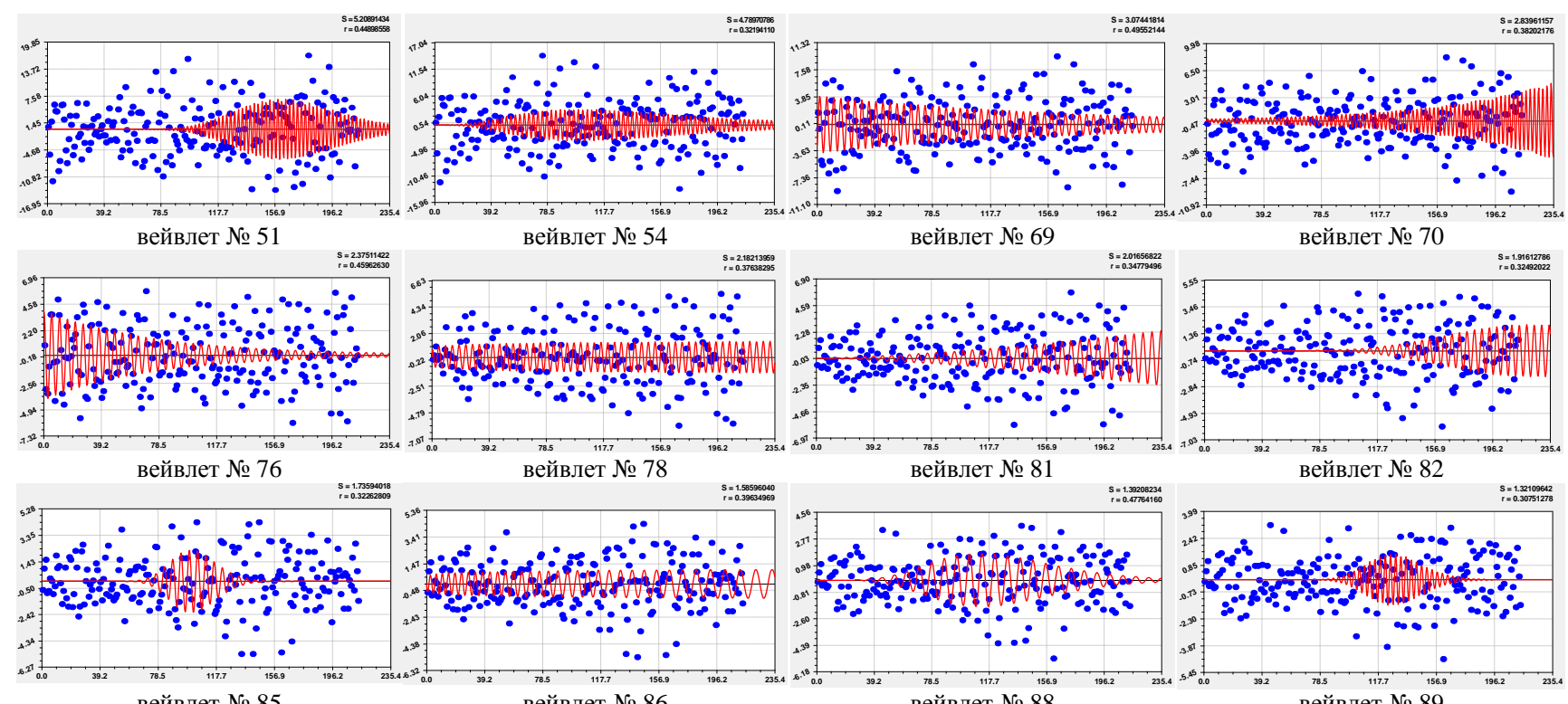

вейвлет № 85

вейвлет № 86

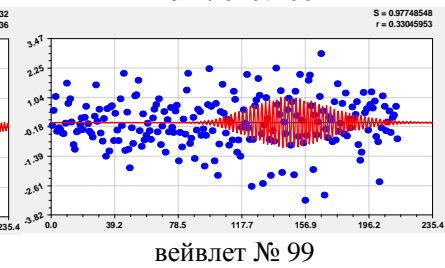

вейвлет № 88
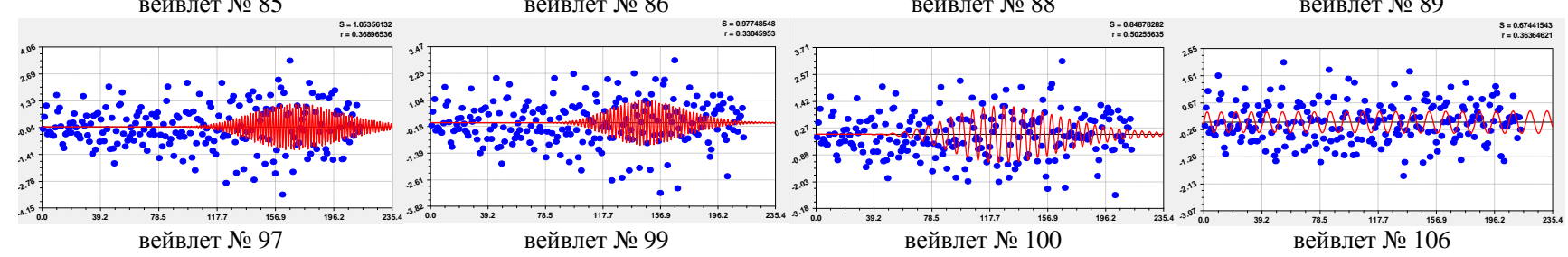

Рис. 7. Графики вейвлетов (табл. 2) динамики ширины годичного слоя дуба № 5

с коэффициентом корреляции не менее 0,3

Из графиков на рис. 7 видно, что многие вейвлеты произошли в прошлом. Поэтому вейвлетанализ дает возможность составить прогнозную математическую (статистическую) модель.

\section{ПРОГНОЗИРОВАНИЕ ПОВЕДЕНИЯ ДУБА ПО ШИРИНЕ ГОДИЧНОГО СЛОЯ}

Компьютер дал ту последовательность членов, которая поэтапно идентифицируется программной средой CurveExpert-1.40. Череда сигналов от разложения сложного динамического ряда ширины годичных слоев у дуба № 5 не совпадает с номером вейвлета. Но эту череду надо уточнять только после проведения процедуры упаковки всех 107 составляющих общей модели типа (2), а для этого нужен новый программный комплекс, позволяющий одновременно учитывать десятки вейвлетов с несколькими сотнями параметров модели.

Для составления прогнозной модели нужно отобрать те члены, которые с 2004 г. будут влиять на изменение ширины годичного слоя. Вполне очевидно, что появляются новые воздействия, поэтому прогнозирование возможно только условно. Причем с ростом горизонта прогноза вероятность появления расчетной ширины годичного слоя уменьшается (погрешность моделирования возрастает).

Дерево выдерживает взятие до 11-12 кернов [4] без изменения физиологических процессов. Поэтому для проверки прогнозных моделей необходимо в конце 2014 г. отобрать по одному керну с этих же деревьев.

Тогда горизонт прогноза определяем в 10 лет.
В табл. 5 даны результаты расчетов по прогнозной модели, в которой были оставлены следующие члены из табл. 2 с номерами: 1-4, 7-9, 11, 16-21, 26$30,33,34,36,38,39,42,43,45,48,50,51,54-57,61$, $62,65-70,72-74,78-82,84,86,95-98,102,106$. Для основания прогноза для 57 действующих членов взят интервал времени 1980-2004 гг. Отброшенные 50 членов статистической модели мало влияют после 1980 г. на динамику $b$.

Таблица 5. Основание прогноза дуба № 5

\begin{tabular}{c|c|c|c|c|c}
\hline \multirow{2}{*}{ Год } & \multirow{2}{*}{ Время } & \multirow{2}{*}{$\begin{array}{c}b, \\
\text { лет }\end{array}$} & $\times 10^{2}$ мм & \multicolumn{3}{|c}{ Расчетные значения } \\
\cline { 4 - 6 } & & $b_{p}$ & $\varepsilon$ & $\Delta, \%$ \\
\hline 1 & 2 & 3 & 4 & 5 & 6 \\
\hline 1980 & 190 & 88 & 86,3 & 1,7 & 1,93 \\
\hline 1981 & 191 & 90 & 98,4 & $-8,4$ & $-9,33$ \\
\hline 1982 & 192 & 99 & 104,3 & $-5,3$ & $-5,35$ \\
\hline 1983 & 193 & 142 & 140,2 & 1,8 & 1,27 \\
\hline 1984 & 194 & 134 & 129,6 & 4,4 & 3,28 \\
\hline 1985 & 195 & 103 & 97,2 & 5,8 & 5,63 \\
\hline 1986 & 196 & 84 & 79,1 & 4,9 & 5,83 \\
\hline 1987 & 197 & 91 & 100,0 & -9 & $-9,89$ \\
\hline 1988 & 198 & 90 & 88,4 & 1,6 & 1,78 \\
\hline
\end{tabular}

Окончание таблицы 5

\begin{tabular}{c|c|c|c|c|c}
\hline 1 & 2 & 3 & 4 & 5 & 6 \\
\hline 1989 & 199 & 106 & 117,1 & $-11,1$ & $-10,47$ \\
\hline 1990 & 200 & 113 & 107,7 & 5,3 & 4,69 \\
\hline 1991 & 201 & 110 & 109,3 & 0,7 & 0,64 \\
\hline 1992 & 202 & 92 & 81,6 & 10,4 & 11,30 \\
\hline 1993 & 203 & 70 & 68,6 & 1,4 & 2,00 \\
\hline 1994 & 204 & 56 & 59,5 & $-3,5$ & $-6,25$ \\
\hline
\end{tabular}




\begin{tabular}{c|c|c|c|c|c}
\hline 1995 & 205 & 74 & 80,5 & $-6,5$ & $-8,78$ \\
\hline 1996 & 206 & 71 & 75,6 & $-4,6$ & $-6,48$ \\
\hline 1997 & 207 & 66 & 68,1 & $-2,1$ & $-3,18$ \\
\hline 1998 & 208 & 64 & 55,9 & 8,1 & $\mathbf{1 2 , 6 6}$ \\
\hline 1999 & 209 & 72 & 66,9 & 5,1 & 7,08 \\
\hline 2000 & 210 & 86 & 77,3 & 8,7 & 10,12 \\
\hline 2001 & 211 & 75 & 82,4 & $-7,4$ & $-9,87$ \\
\hline 2002 & 212 & 66 & 71,0 & -5 & $-7,58$ \\
\hline 2003 & 213 & 72 & 79,7 & $-7,7$ & $-10,69$ \\
\hline 2004 & 214 & 81 & 80,8 & 0,2 & 0,25 \\
\hline
\end{tabular}

Без 50 членов с 1980 по 2004 гг. основание прогноза дает максимальную относительную погрешность $12,66 \%$.

Статистическая модель по табл. 2 дает возможность прогноза на одну треть полного основания 230 / 3 до 2080 г.

В табл. 6 с учетом повышающейся погрешности моделирования дан прогноз до 2050 г.

Осенью 2014 г. появится практическая возможность проверки прогноза за 2005-2014 гг.

\section{ЗАКЛЮЧЕНИЕ}

Идентификация устойчивых закономерностей позволяет преобразовать табличные модели, которых много накопилось в дендрохронологии, например в [6], в высокоадекватные волновые уравнения с переменными амплитудами и периодами колебательного возмущения.

Эта текущая информация о взаимодействии растущего дерева со своей окружающей средой запоминается в годичных слоях древесинного тела дерева [7]. Тогда появляется задача дешифровки записанной информации в виде отдельных колебаний некоторой длины в хронологическом времени.

За свою жизнь в главном стебле дерева накапливается множество волн возмущения живых клеток при их одревеснении. При этом принимается допущение, что усушка керна древесины до проведения измерений вызывает пропорциональные изменения в размерах клеток и годичных слоев.

Применение предложенных методов и методик [7-18] к коротким рядам до 150-250 лет не представляет особых трудностей. Однако процесс идентификации весьма трудоемкий.

Таблица 6. Прогноз ширины годичного слоя дуба

\begin{tabular}{r|r|r|r|r|r|r|r|r}
\hline Год & $\begin{array}{l}\text { Время } \\
t, \text { лет }\end{array}$ & $\begin{array}{c}b_{p}, \\
\times 10^{2} \text { мм }\end{array}$ & Год & $\begin{array}{c}\text { Времяя } \\
t, \text { лет }\end{array}$ & $\begin{array}{c}b_{p}, \\
\times 10^{2} \text { мм }\end{array}$ & $\begin{array}{l}\text { Год } \\
\text { Время }\end{array}$ & $\begin{array}{c}b_{p}, \\
t, \text { лет }\end{array}$ \\
\hline 2005 & 215 & 68,5 & 2021 & 231 & 83,1 & 2037 & 247 & 77,1 \\
\hline 2006 & 216 & 52,5 & 2022 & 232 & 56,8 & 2038 & 248 & 107,4 \\
\hline 2007 & 217 & 73,2 & 2023 & 233 & 77,2 & 2039 & 249 & 34,9 \\
\hline 2008 & 218 & 95,8 & 2024 & 234 & 98,1 & 2040 & 250 & 52,3 \\
\hline 2009 & 219 & 100,2 & 2025 & 235 & 123,6 & 2041 & 251 & 78,4 \\
\hline 2010 & 220 & 79,2 & 2026 & 236 & 124,5 & 2042 & 252 & 55,4 \\
\hline 2011 & 221 & 107,1 & 2027 & 237 & 97,5 & 2043 & 253 & 73,4 \\
\hline 2012 & 222 & 106,3 & 2028 & 238 & 109,6 & 2044 & 254 & 123,0 \\
\hline 2013 & 223 & 110,5 & 2029 & 239 & 151,0 & 2045 & 255 & 64,4 \\
\hline 2014 & 224 & 76,5 & 2030 & 240 & 128,5 & 2046 & 256 & 84,2 \\
\hline 2015 & 225 & 72,1 & 2031 & 241 & 105,9 & 2047 & 257 & 44,8 \\
\hline 2016 & 226 & 74,9 & 2032 & 242 & 140,5 & 2048 & 258 & 17,0 \\
\hline
\end{tabular}

\begin{tabular}{l|l|l|l|l|l|l|l|r}
\hline 2017 & 227 & 87,9 & 2033 & 243 & 79,5 & 2049 & 259 & 60,4 \\
\hline 2018 & 228 & 54,0 & 2034 & 244 & 76,4 & 2050 & 260 & 100,5 \\
\hline 2019 & 229 & 72,3 & 2035 & 245 & 91,0 & & & \\
\hline 2020 & 230 & 78,1 & 2036 & 246 & 63,4 & & & \\
\hline
\end{tabular}

Поэтому для автоматизации моделирования необходима разработка специализированной программной среды. Она может быть создана на базе наших методик эвристической, структурной и параметрической идентификации устойчивых законов распределения.

Дендроэкологический мониторинг прошлого у территории, на которой произрастает древостой, возможен по модельным и учетным деревьям, а также по отведенным лесоводами в рубку деревьям хозяйственного назначения. Вместе с тем дендроэкологический мониторинг и потребность в надежных экологических прогнозах, как было показано в данной статье, потребует перехода к учетным деревьям и применения в будущем неразрушающих и частично разрушающих (многократным взятием кернов из стволов и ветвей испытуемых деревьев) методов дендрохронологии.

\section{СПИСОК ЛИТЕРАТУРЫ}

1. Бюсген М. Строение и жизнь наших лесных деревьев/ Пер. с нем. М.-Л.: Гослесбумиздат, 1961. 424c.

2. Варсегова Л.Ю., Мазуркин П.М., Фадеев А.Н. Практикум по экологическому древоведению / под ред. проф. П.М. Мазуркина. Йошкар-Ола: МарГТУ, 2010. 42 с.

3. Верхунов П.М., Мазуркин П.М. Таксация древесного ствола лесных насаждений: Учеб. пос. Йошкар-Ола: МарГТУ, 1999. $72 \mathrm{c}$.

4. Колесникова А.А. Исследование свойств древесины по кернам. Йошкар-Ола: МарГТУ, 2002. 178 с.

5. Использование кернов древесины в лесоводственных исследованиях: Метод. рекомендации / Д.П. Столяров, О.И. Полубояринов, Н.Н. Декатов и др. Л.: ЛенНИИЛХ, 1988. $43 \mathrm{c}$.

6. Ловелиус Н.В. Изменчивость прироста деревьев. Дендроиндикация природных процессов и антропогенных воздействий. Л.: Наука, 1979. 232 с.

7. Мазуркин П.М. Дендрометрия. Статистическое древоведение: учеб / пос. Часть 1. Йошкар-Ола: МарГТУ, 2003. $308 \mathrm{c}$.

8. Мазуркин П.М. Дендрохронологические шкалы разновозрастного сосняка // Современные наукоемкие технологии. № 6. 2010. С. 32-44.

9. Мазуркин П.М. Дендрохронологические шкалы и возрастная структура разновозрастного сосняка. 12 с. Портал WOOD.RU. URL: http://www.wood.ru/ru/loa732.html.

10. Мазуркин П.М. Решение 23-ой проблемы Гильберта // Междисциплинарные исследования в области математического моделирования и информатики. Матер. 3-й научно-прак. internet-конф. Ульяновск: SIMJET, 2014. C 269-277.

11. Мазуркин П.М. Статистическое моделирование многоцикловых процессов // Циклы природы и общества: материалы VI Международной конференции. Часть 1. Ставрополь: Изд-во Ставр. ун-та, 1998. С. 213-218.

12. Мазуркин П.М., Варсегова Л.Ю. Испытание растущего дерева // Успехи современного естествознания. № 4. 2010. C. 38-43. 
13. Мазуркин П.М., Варсегова Л.Ю. Измерение ширины годичного слоя на керне древесины // Успехи современного естествознания. № 4. 2010. С. 31-38.

14 Мазуркин П.М., Варсегова Л.Ю. Измерение ширины годичных слоев сердцевины и присердцевинной зоны растущего дерева с использованием кернов // Деревообр. пром-сть. 2010. № 2. С. 25-26.

15. Мазуркин П.М., Варсегова Л.Ю. Ультразвуковое испытание древесины растущего дерева на радиальных кернах // Деревообр. пром-сть. 2010. № 3. С. 29-30.

16. Мазуркин П.М., Демаков Ю.П. Особенности многоволновой динамики радиального прироста сосны // Циклы природы и общества: материалы VI Международной конференции. Часть 2. Ставрополь: Изд-во Ставр. ун-та, 1998. C. 174-176.

17. Мазуркин П.М., Филонов А.С. Математическое моделирование. Идентификация однофакторных статистических закономерностей: учебное пособие. Йошкар-Ола: МарГТУ, 2006. 292 с.

18. Мазуркин П.М., Филонова Е.С. Метод анализа дендрометрических данных // Экология: Образование, наука, промышленность и здоровье: материалы II Международной научно-практической конференции. Вестник БГТУ. 2004. № 8. Часть V. C. 83-85.

19. Тишин Д.В. Дендроэкология (методика древеснокольцевого анализа): учебно-метод. пос. Казань: Казанский университет, $2011.33 \mathrm{c}$.

20. Шиятов С.Г. и др. Методы дендрохронологии. Часть I. Основы дендрохронологии. Сбор и получение древесно-кольцевой информации: Учебно-методическое пособие. Красноярск: КрасГУ, 2000.80 с.

21. Douglass A.E. Climatic cycles and tree-growth. A study of the annual rings of trees in relation to climate and solar activity. - Washington: Carnegie Inst., 1919. Vol. 1. 127 p.

22. Mazurkin P.M. «Wavelet Analysis of a Number of Prime Numbers» . American Journal of Numerical Analysis, vol. 2, no. 2 (2014): 29-34. doi: 10.12691/ajna-2-2-1.

23. Rinn F. TSAP-Win - time series analysis and presentation: dendrochronology and related applications. Heidelberg, Germany. 2003. 91 p.

\title{
WAVE DYNAMICS OF TREE-RING WIDTH OF OAK
}

\author{
(C) 2014 P.M. Mazurkin ${ }^{1}$, D.V. Tishin ${ }^{2}$ \\ ${ }^{1}$ Volga State University of Technology \\ ${ }^{2}$ Kazan Federal University
}

\begin{abstract}
An tree-ring width analysis was conducted on cores of 7 oaks (Querqus robur L.) growing near town of Zelenodolsk in Tatarstan Republic. Mathematical model of annual tree-rings growth dynamics for tree №5 is presented. The model described consists of more than 100 asymmetric wavelet signals. This enables future heuristic identification of causes of every wave of radial-growth. The matrix of model parameters is given, as well as comparison of oaks on biological timing and graphical representation of relationships revealed. The prognosis till 2050 of tree-ring width for tree №5 is given.
\end{abstract}

Key words: oak, tree-ring width, radial growth, dynamics, wavelets, comparison 